\title{
Editorial
}

\section{EL REINADO DE LOS RANKINGS}

Juan Carlos Villalba Cuéllar (Editor)
Andrés González Serrano (Coeditor)

DOI: http://dx.doi.org/10.18359/prole.3326

Hoy en día la medición de la calidad de la educación está altamente influenciada por los rankings, es decir, por los posicionamientos que ciertas empresas o entidades publican de las universidades en razón a diferentes criterios de medición, los cuales siempre varían. Los medios de comunicación están siempre atentos a volverlos noticia sin mayor análisis, tal como es propio de un mundo en que predomina la desinformación mediática inmediatista. Los ciudadanos y en especial los que estamos involucrados con la educación, los miramos con curiosidad, para buscar siempre en dónde estará o estarán las universidades con las que tenemos algún vínculo o filiación, para saber supuestamente cuáles son las mejores.

Sin embargo, este reinado de rankings deja un espacio a la reflexión y plantea una pregunta: ¿qué tan importantes deben los rankings para una institución educativa? Lo primero es cuestionarnos sobre si una facultad o universidad debe comenzar a gravitar alrededor de la clasificación que tenga en uno $\mathrm{u}$ otro ranking, $\mathrm{y}$ si allí deben estar encaminadas las prioridades de la educación. Lo segundo es el interrogante sobre si debe primar la valoración cuantitativa o cualitativa de la educación.

Ahora bien, lo que diga un ranking -estar en él o no y tener en cuenta la posición en el listado- no necesariamente refleja la calidad de una universidad o programa. La educación es un proceso integral, que involucra demasiados factores como para pretender que pueda ser medida completamente por estudios que siempre serán parciales.
No se puede olvidar tampoco que las universidades cuya oferta académica se centre en campos del saber ligados a las ciencias sociales, por razones obvias no aparecerán en puestos privilegiados de rankings que miden número de publicaciones en revistas científicas, hablando de ciencias duras, que es lo que generalmente se mide. Por esto, en las facultades de derecho y de ciencias sociales debe tomarse con cautela dichos rankings $y$ fijarse primero que midan parámetros acordes a la realidad de su área del saber.

Con respecto al segundo interrogante se puede afirmar que los rankings pueden ayudar en lo cuantitativo, pero debe tenerse en cuenta que los diferentes rankings miden diversos factores, algunos se centran en aspectos netamente investigativos, tales como publicaciones de sus profesores en revistas "científicas", premios nobel obtenidos, profesores con doctorado, patentes obtenidas, entre otros. Mientras que otros rankings pretenden tener en cuenta prestigio de los profesores, la empleabilidad de los egresados, la reputación de la universidad en medios especializados o medios laborales, o simplemente los resultados de unas pruebas estatales como sucede en Colombia con las pruebas SABER. De esta forma podemos darnos cuenta que los rankings no siempre miden lo mismo, y un ranking netamente cuantitativo puede estar dejando de lado factores importantes de la educación para medir su calidad. De la misma forma un ranking que sea netamente cualitativo no podría revelar si en cifras los resultados del proceso educativo son idóneos, es decir, que también mostraría resultados parciales. Tal vez por eso la mezcla entre lo cualitativo y lo cuantitativo es necesaria. 
Infortunadamente los rankings logran distraer algunas discusiones que en contextos de subdesarrollo como el colombiano deben tener verdadera relevancia, pues a veces pareciera sentirse un clamor mediático o social porque algunas de nuestras universidades aparezcan en esos rankings para regocijarnos patrióticamente de un logro. Más que el ranking debería preocuparnos la mejora en general de la cobertura y la calidad de la educación en nuestro país.

Así las cosas, un ranking debe leerse con reserva antes de sacar conclusiones ligeras y no podemos en las universidades y facultades de derecho volvernos esclavos de él, o permitir que la educación se dirija solamente a mejorar indicadores, sin procesos serios que conduzcan a mejoras reales en la educación y formación humana de los estudiantes.

La misión de la actividad educadora va muchos más allá de aparecer en un ranking, aunque si la lógica impera, una universidad que esté haciendo bien la tarea de educar, con responsabilidad social y altos índices de calidad académica, debería aparecer en los rankings, y si no aparece dará igual, puesto que la conciencia y tranquilidad que lo fundamental se está cumpliendo a cabalidad es una realidad. El ranquin siempre será secundario bajo esta perspectiva. 